\title{
Samos Heraion ve Ephesos Artemis Kutsal Alanlarındaki Oryantal Objeler*
}

\author{
The Oriental objects from the Heraion of Samos and the Artemision of Ephesus \\ Sanctuaries
}

\begin{abstract}
Kenan EREN**
Özet: Özellikle Arkaik Dönem başında Ionia kutsal alanları zengin buluntu kontekstleri sergilemektedir. $\mathrm{Bu}$ alanlarda pek çok ithal objenin bulunması Doğu ile yeni oluşturulmuş iletişim ağlarının bir sonucu olabilir. Oryantal objelerin sunularda kullanımı, bazı tip nesnelere bu dönemde özel bir ilgi olduğunu düşündürmektedir. Anlaşılan Yakın Doğu'nun büyük güçleri ile ilişkilerin güçlenmesi ve Akdeniz Dünyası ile devamlı bağlantıda olmak bu dönem görülen değişimlerin biçimlenmesinde özel bir öneme sahiptir. Yine de bu dönüşümün bütün kutsal alanlarda aynı biçim veya aynı yoğunlukta olmadığı gözlemlenebilir. Dolayısıyla kutsal alan kontekstlerinin daha detaylı olarak incelenmesi İ.Ö. VII. yüzyılda görülen değişimlerin doğası ve limitlerini anlamak için kritik bir değere sahiptir. Bu yüzden Samos Heraion ve Ephesos Artemision gibi bölgenin çok önemli iki kutsal alanının sunu objelerinin karşılaştırılmalı olarak incelenmesi, tarihsel arka plan hakkında önemli ipuçları verme potansiyeline sahip görünmektedir.
\end{abstract}

Anahtar Sözcükler: Ionia, İ.Ö. VII. yüzyıl, bağlantı, kutsal alanlar, sunu objeleri, oryantal periyod

Abstract: Especially during the beginning of the archaic period, Ionian sanctuaries display a rich material content. The presence of an important amount of foreign objects in these sanctuaries can be considered as a result of the newly established communication network with the East. The redistribution of oriental objects as offerings allows us to assume the existence of a constant interest in certain types of objects. It seems that a constant and continuous connectivity within the Mediterranean regions and the intensification of relations with major powers of the Orient have a particular importance in all the changes at that time. However, it appears that this mutation does not work in all the sanctuaries to the same extent and in the same way, and a deeper study of the contexts of sanctuaries is critical to understand the nature and limits of the changes during the seventh century. A comparison of the Heraion Samos and Artemison Ephesos, two very significant sanctuaries of the region may provide further information about the historical context.

Keywords: Ionia, VII. century B.C., connectivity, sanctuaries, offerings, oriental period

Perregrine Horden ve Nicholass Purcell'ın yazdı̆̆ı ve 2000 yılında yayınlanmış olan The Corrupting Sea kitab1 (Horden, \& Purcell, 2000) her şeyden önce Fernand Braudel'in Akdeniz'ine alternatif (Braudel, 1989), long durée kavramını farklı bir bakış açısıyla ele almayı amaçlayan bir yapıt olma iddiasındadır (Etienne, 2006; Harris, 2005). Yazarlar Akdeniz tarihi ile ilgili çalışmalarında, politik, dinsel, sosyal ve ekonomik olguların bir araya gelerek oluşturdukları karmaşık iletişim ağları (network) üzerinden bu tarihi değerlendirmişlerdir. Öne

\footnotetext{
* Bu makale, 2011 ve 2012 yıllarında SOMA sempozyumlarında tarafımdan sunulmuş olan "Ionian Sanctuaries and the Mediterranean World in the Seventh-Century B.C." ve "Heraion of Samos and Artemision of Ephesos in the Archaic Period: A Comparison" isimli iki bildirinin ana fikirlerinin, yeniden gözden geçirilerek yayına hazırlanmış halidir.

** Yrd. Doç. Dr, Mimar Sinan Güzel Sanatlar Üniversitesi, Arkeoloji Bölümü, İstanbul, kenan.eren@msgsu.edu.tr
} 
sürdükleri tezlerinden bir tanesi, Akdeniz'in her biri kendi özgün niteliklerini taşıyan mikrobölgeciklerden oluştuğu ve bu bölgeler arasında da devamlı bir bağlantı (connectivity) olduğudur. İ.Ö. VII. yüzyılda bu bağlantının özellikle güçlendiği dönemlerden birisidir ve her bölge "Akdenizleşme"ye (mediteranisation) farklı tepkiler gösterse de, bölgesel düzeyde değişimler ancak Akdeniz ölçeğindeki halk ve mal hareketleri ile anlaşılabilir.

Dolayısıyla, yazarların mantığını izleyerek Ionia Bölgesi’nde İ.Ö. VII. yüzyılı sorgularsak, bütün bu Akdeniz ölçeğindeki ilişkiler ağının yerel düzeyde izlerinin görülmesi mümkün olacaktır. Bölgede bu dönemde gözlenebilen en önemli değişiklik, İ.Ö. VII. yüzyılda hem pek çok yeni kutsal alanın ortaya çıkması, hem de Demir Çağı'ndan beri var olan kutsal alanların mekansal organizasyonlarında önemli değişiklikler olmasıdır. Bu makalede de, hem bu mekânsal organizasyon değişiklikleri, hem de söz konusu kutsal alanlardaki belli başlı sunu objesi tiplerinde görülen değişiklikler, Ionia Bölgesi'nin Arkaik Dönem başında Akdeniz Dünyası ile ilişkileri kapsamında yorumlanmaya çalışılacaktır.

İ.Ö. VII. yüzyılda, Ionia Bölgesi kutsal alanlarında anıtsal ölçekte yeni teras duvarlarının inşa edilmesi ve bazı yeni mimari öğelerin bu alanlarda görünmeye başlaması hemen dikkati çekmektedir. Bu yapıların kesin fonksiyonunu belirlemek her zaman mümkün olmasa da, Demir Çağı kutsal alanlarından farklılaşan bir mekansal düzenleme söz konusudur ve buna paralel olarak sunu objesi kontekstlerinde de önemli değişiklikler gözlenmektedir. Bu değişimlerin yakından incelenmesi, hem ekonomik hem de sembolik olarak "değerli" bazı objelerin Akdeniz boyunca dolaşımını anlamak ve Ionia'nın Akdeniz Dünyası ile bu dönemde kurduğu ilişkileri daha iyi tanımlamak açısından da önemli gözükmektedir.

Sunu objelerinin incelenmesi bir kutsal alanın veya o alanın tanrı(ça)sının kent veya bölge hayatında oynadığı rolle ilgili bilgi verme potansiyeline sahiptir (Patera, 2006, 363). Bir objenin belli bir kontekste sunulması kararı, bilinçli tercihlerin bir sonucudur ve bu tercihleri kültün doğası veya tanrı(ça)nın özellikleri ile ilişkilendirmek, özellikle Arkaik Dönemde aynı tip objelerin çoğu zaman farklı tanrı(ça)lara sunulmuş olması nedeniyle genelde yetersiz kalmaktadır (Simon, 1986, 419). Buna karşılık sunu objeleri birey veya grupların varlıklarını kamusal alanda duyurmak amacıyla izledikleri farklı stratejiler bağlamında değerlendirilebilir. Bunların yerel habitus'la bağlantılı olarak şekillendiklerini kabullenerek sunu objesi kontekstlerini değerlendirmeye başlanırsa, bu objelerin kutsal alanlara dağılımını belirli bir tanrı(ça) imgesinden bağımsız olarak analiz edilebilir. Her halükarda, özellikle ithal objelerin farklı kutsal alanlarda ama benzer biçimlerde kullanımı, dinsel anlamlarından ziyade sosyal anlamları üzerinde yoğunlaşarak bir çözümleme denemesini gerektirmektedir.

Ionia'da Geometrik Dönem kutsal alanlarından günümüze kalan mimari kalıntılar son derece sinırlıdır ve Protogeometrik ve Geometrik Dönem için en önemli buluntu gurubunu pişmiş toprak hayvan heykelcikleri oluşturur. Geometrik kutsal alanların erken evreleri de genellikle bir peribolos 'la çevrili teraslardan oluşmaktadır. Figürinler ve diğer sunu objeleri her zaman sunaklar veya daha sonraki evrelerde sunağın inşa edileceği alanlar etrafindan ele geçmektedir. Bu dönem kutsal alanlarının, özellikle su kaynakları ile ilişkili olarak konumlandıkları da söylenebilir. Ephesos'taki Artemis kutsal alanı, bu dönemde bir tapınak yapısına sahip tek örneği oluşturmaktadır. Burada İ.Ö. VIII. yüzyılda inşa edilmiş olan peripteros, varlığını İ.Ö. VII. yüzyılda da sürdürmüştür (Bammer, 1991, 73, Bammer, 2008, 43).

Buna karşıllk İ.Ö. VIII. yüzyıl sonundan itibaren, ama özellikle İ.Ö. VII. yüzyıl da bu alanlarda önemli değişiklikler gözlenmektedir. Yeni terasların inşası ve bazı ortak aktiviteler için kullanıldığı anlaşılan mekanların ortaya çıkmasının yanı sıra en çarpıcı değişiklik, sunu obje tiplerinin büyük çeşitlilik kazanması ve pek çok değerli objenin sunu objesi olarak kullanılmaya başlamasıdır. Özellikle oryantal objelerin bol miktarda kullanılmaya başlanması, bu dönemde görülen değişikliklerin en önemlisi olarak görünmektedir. (Makalede oryantal sunu 
objeleri olarak bahsedilecek eser grubu temelde Misır, Kuzey Suriye, Suriye-Filistin sahileri, İran ve Anadolu'nun iç bölgelerinde imal edilip, daha sonra Ionia kutsal alanlarında sunulmuş çeşitli objeleri kapsamaktadır. Bunlar küçük heykelciklerden, çeşitli süs eşyalarına ya da değerli madenlerden kaplara kadar büyük değişiklilik gösteren ürünler olabilirler. Kutsal alanlarda ele geçen bu tip objeler için "oryantal" terimi nadiren kullanılmaktadır ve İngilizce'de genelde bu tip malzeme için foreign artefact terimi tercih edilmektedir. Almanca'da ise objenin kutsallığına vurgu yapan fremde Weihungen'in daha sıklıkla kullanıldığı gözlemlenebilir (Kilian-Dirlmeier, 1985; Guralnick, 1992). Ancak özellikle W. Burkert'in önemli çalışmasından sonra (Burkert, 1992) yukarıda bahsedilen coğrafyaya özgü tüm kültürel üretimler için "oryantal" terimi daha sıklıkla kullanılmaya başlanmıştır (terminolojinin tarihçesi ile ilgili daha detaylı bir tartışma için, bkz. Saint Pierre, 2005, 11-15). Bu makalede de, söz konusu objelerin kökenini daha iyi vurgulayabilmek için oryantal objeler olarak tanımlanmaları uygun görülmüştür).

Aslında Ionia'da oryantal obje sunularına İ.Ö. VIII. yüzyılda da rastlanmaktadır ancak bunlar genelde ustalıkla şekillendirilmiş ve çok değerli objelerdir. Buna karşıllı İ.Ö. VII. yüzyılda, oryantal objelerin hem sayısı, hem de çeşitliliği önemli ölçüde artar ve büyük ölçekli üretimle ilişkilendirilebilecek daha ucuz objeler de sıklıkla sunulmaya başlanır. Samos Heraion, Ephesos Artemision, Khios Emporio Liman Kutsal Alanı ve Apollon Phanai, Miletos Athena ve Aphrodite kutsal alanları, Didymaion ve Klaros Apollon Kutsal Alanları, Smyrna ve Erythrai Athena tapınaklarında farklı miktar, orijin ve biçimlerde oryantal objelerin varlığ 1 gözlemlenebilir (Saint Pierre, 2005).

L. Foxhall'ın belirttiği gibi bu dönemde deniz aşırı ülkelerden gelen her türlü eşyaya karşı büyük bir istek bulunmaktadır (Foxhall, 1998, 301-303). Her ne kadar kapasite ve organizasyon hakkında çok sınırlı bilgiye sahip olsak da bütün bu objelerin varlığı, Doğu Akdeniz ile Hellen Dünyası arasında değiş-tokuş aktiviteleri ve düzenli bir ilişkinin var olduğu fikrini uyandırmaktadır (bu ilişkilerin niteliği ve aktörleri ile ilgili pek çok teori ve geniş bir bibliyografya bulunmaktadır, tartışmaların bir özeti ve güncel paradigmalar için bkz. Etienne, 2010, 3-21). Yine de bu ilişkiler ağına her Hellen kentinin farklı tepkiler verdiğini ve bazı kentlerin daha aktif roller üstlendiğini varsaymak mümkündür. Bu objelerin Ionia kutsal alanlarına dağılımının incelenmesi, Akdeniz Dünyası ile Ionia arasında gelişmekte olan ilişkilerin doğasını anlama yönünde önemli ipuçları verme potansiyeline sahiptir.

Özellikle kent merkezleri dışında kalan kutsal alanlarda ithal obje sayısı ve çeşitliliği daha fazla görülmektedir. Yine altı çizilmesi gereken bir başka nokta, oryantal objelerin yoğun olarak ele geçtiği kutsal alanların denizle kurduğu yakın ilişkidir. En çok ithal sunu objesi ele geçen kutsal alanlardan Samos Heraion, Khios Apollon Phanai ve Emporio liman kutsal alanları denize çok yakın olarak konumlanmışlardır ve her biri bir limana sahiptir (Samos Heraion için Kyrieleis, 1993, 136; Khios Apollon Phanai için Beaumont, \& Archontidou-Argyri, 1999, 282; Khios Emporio için Boardman, 1967, 53). Bunun ötesinden bu alanlarda denizden giriş için özel düzenlemelerin yapıldığı görülebilmektedir. Bir diğer önemli buluntu grubu ise Miletos'a yaklaşan gemilerin uzaktan görüp, nirengi noktası olarak kullanabileceği bir tepede yer alan Aphrodite kutsal alanıdır (Gans, 1991, 137: Yazar Kalabaktepe'nin daha yüksek olmasına karşılık, Aphrodite kutsal alanının bulunduğu Zeytintepe'nin Miletos'a doğru seyreden gemiler için daha görünür bir konumda olduğunun altını çizer; bkz ayrıca Senff, 2006, 169), ayrıca Miletos Athena kutsal alanı liman bölgesinde yer alması sebebiyle bu guruba girmeyi hak etmektedir (Greaves, 2000, 42). Buna karşılık limanı olan bir diğer kutsal alan Ephesos Artemision'da bulunan sunu objeleri farklı bir panorama ortaya koymaktadır. Bunların dışında Smyrna ve Erythrai Athena tapınaklarında yapılan kazılar da, Yakın Doğu ve Mısır kökenli pek çok sunu objesinin varlığını ortaya koymuştur (Smyrna için Cook, 1951, 249 ve Saint-Pierre, 2005, 368; Erythrai için Bayburtluoğlu, 1975, 71 ve Bayburtluoğlu, 1977, 3, ayrıca Gültekin, 1968). 
Bütün bu veriler, Akdeniz'in uzak bölgeleriyle kurulan ilişkileri yansıtan eşyaların ritüellerde daha "görünür" bir hale geldiğini göstermektedir. Anlaşılan "connectivity" olarak tanımlanan fenomen, İ.Ö. VII. yüzyı1 Ionia'sında da gözlemlenebilmektedir. Uluslararası dolaşım ağlarına katılımın, özellikle kült aktivitelerinde kullanılan objelerle ilgili tercihleri etkilediği anlaşılmaktadır. Ancak bu duruma yerel düzeyde farklı tepkiler geliştirildiği de gözlemlenebilir. Aynı döneme tarihlenen iki kutsal alan olan Klaros Apollon ve Emporio Athena'da ki emporyon'da yerel üretim pişmiş toprak heykelciklerin sunumunun tercih edilmesi, topluluk içinde bazı grupların ithal sunu objelerini kullanmaktan kaçındığı örneklerin de var olduğunu göstermektedir (Klaros Apollon heykelcikleri için Dewailly, 2001, 367-368; Khios Emporio Athena buluntuları için Boardman, 1967, 28-29, ayrıca bkz. Simon, 1997: yazar bu makalesinde Emporio'daki Athena ve liman kutsal alanlarının sunu obje kontekstlerinin karşıt karakterlerini incelemektedir).

Bütün bu kutsal alanlar içerisinde, Samos Heraion ve Ephesos Artemision sergiledikleri sunu objesi miktarı ve çeşitliliği açısından Ionia'daki diğer bütün kutsal alanlara büyük fark atarlar. Bir diğer önemli nokta, bu iki alanda da ele geçen sunu objelerinin büyük bir kısmının yüksek maddi değere sahip olmasıdır. Bu kutsal alanların bütün bölge içerisinde özel bir öneme sahip oldukları ve toplumun üst kademelerinde yer alan ziyaretçilerin sıklıkla bu alanları ziyaret ettikleri anlaşılmaktadır. Linders'in belirttiği gibi, değerli sunu objelerinin miktarı, o kutsal alanın ve tanrı(ça)sının prestiji ile doğrudan ilişkilidir (Linders, 1987, 118). Dolayısıyla bu iki alan kontekstinin daha detaylı bir karşılaştırması, Akdeniz Dünyası ile kurulan ilişkilerin yerel kontekste nasıl yansıdığı ile ilgili pek çok ipucunu ortaya çıkarabilir.

Ephesos Artemis kutsal alanı deniz kıyısında yer alır ve limanı tapınağın yaklaşık 100 metre batısında konumlanmıştır. Kutsal alanın doğu kısmında bir dizi küçük dere bulunmaktadır ve kuzeyi muhtemelen kutsal alanın ilk evrelerinde denizle çevrilidir (Kraft, Kayan, Brückner, Rapp, 2000, 185-186, Kraft, Kayan, \& Brückner, 2001, 129). Artemision tarihi boyunca hep Ephesos kenti surları dışında kalmıştır ve arkaik Ephesos kentinin iki adet tahkimli çekirdek etrafinda şekillendiği düşünülebilir (Tréziny, 2006, 243-245). Artemision'un bu dönemde göreceli olarak bağımsız bir görüntü çizdiği söylenebilir. Geç Bronz Çağı ve Protogeometrik Geometrik Dönem başı buluntularını pişmiş toprak figürinler oluşturur (Forstenpointner, Kerschner, \& Muss, 2008, 39-40). Daha önce söylediğimiz gibi, Ephesos Artemision'da bir peripteros daha İ.Ö. VIII. yüzyılda inşa edilmiştir ve bu yapı varlığını İ.Ö. VII. yüzyıl boyunca sürdürür. Bunun yanında İ.Ö. VII. yüzyıl boyunca her biri kült aktiviteleri için kullanılmış bir dizi dikdörtgen kaidenin kutsal alana yayıldığını görebilmekteyiz. Bunların etrafındaki kurban kalıntıları ve sunu objeleri bu kaidelerin kült amaçlı kullanımı ile ilgili kanıtları oluşturmaktadır (Bammer, 1991a, 127-130). Ayrıca apsidal planlı bir yapının peripteros'un güneyinde inşa edildiği de görülmektedir. İ.Ö. VII. yüzyılın sonuna doğru kalkerden C Tapınağı yanı sıra mermer hekatompedo'nun da kutsal alanda yer aldıkları gözlenebilmektedir (Bammer, 1993, 191). Bütün bu farklı strüktürlerin bir arada olması A. Bammer (1991/1992) tarafından kutsal alanın İ.Ö. VII. yüzyıl boyunca aynı anda birden çok "cemaat" tarafından kullanılmış olabileceği şeklinde yorumlanmıştır.

Kutsal alanda İ.Ö. VII. yüzyıla tarihlenen ve büyük bir kısmı takı eşyaları, amuletler ve kadın figürleri olmak üzere değerli taş ve madenlerden binlerce sunu objesi ele geçmiştir (Bammer, 1998, 35: sunu objelerinin kadın dünyası ile ilişkisinin altını çizmektedir). Amber, fildişi, altın, bronz objelerin büyük kısmı Ephesos çevresinde veya Küçük Asya'nın iç bölgelerinde üretilmiştir. Amber objelerin özellikle cella içerisinde dikdörtgen kaide olarak adlandırılan alandan geldiği görülmektedir ve Muss bunların xoanon'a ait bir kolyenin parçaları olduğunu düşünmektedir. (Toplamda 1500 kadar amberden obje bulunmuştur ve bunların 600'ü peripteros'un hemen doğusunda tespit edilmiştir, geri kalanlar ise peripteros'daki dikdörtgen 
kaidenin kuzeyinden gelmektedir, Bammer, 1990, 141 ve Muss, 2008a, 98). Fildişinden üretilmiş objelerin özel bir öneme sahip olduğu anlaşılmaktadır ve bunların büyük bir kısmı İ.Ö. VII. yüzyılın ikinci yarısı ile İ.Ö. VI. yüzyılın ilk yarısı arasına tarihlenirler. İnsan ve hayvan figürinleri yanı sıra, iğneler, broşlar ve çeşitli kült sembolleri görülmektedir ve bunların büyük bir kısmı greko-ionik üsluptadırlar (Muss, 2008b, 106). Toplamda 1000 kadar fildişi objenin ele geçtiği anlaşılmaktadır. Bunlardan küçük bir grubun Kimmer üretimi olduğu düşünülmektedir (Bammer, 1992, 185-204). En büyük buluntu grubunu ise, Doğu Ege ve Batı Küçük Asya kökenli bronzdan takı eşyaları ve hayvan heykelcikleri oluşturur. Kazılarda yaklaşık 2000 adet bronz obje keşfedilmiştir ve özellikle Phrygia kökenli ürünler ve bunların yerel kopyaların büyük miktarlarda sunulduğu görülmektedir (Klebinder-Gauss, 2008, 149-152, kutsal alanda 1500 kadar altından obje ele geçmiştir ve bunların büyük çoğunluğunu arı biçiminde aplikler oluşturur). Benzer bir durum altından yapılma fibulalar ve çeşitli takılar için de geçerlidir ve bunların kutsal alanda sunulmak için tasarlandığı düşünülmektedir (Gschwantler ve Freiberger, 2008, 191). Alanda ithal objelerin sayısı genel toplama göre sinırlıdır ve var olanlar da Kuzey Hellas ve Phrygia kökenlidir (C. Saint Pierre 2005 yılında toplam 205 oryantal obje tespit ettiğini yazmaktadır, Saint Pierre, 2005, 379). Az sayıda Mısır'dan gelme obje de bulunmaktadır (Hölbl, 2008, 215, ayrıca bkz Hölbl, 2008, 281-284, Hölbl 25 kadar Misır kökenli eserden bahsetmektedir). Mevcut yayınlar nicelikten ziyade niteliği ön plana çıkardığ için kesin rakamsal veriler mevcut olmasa da kutsal alanda Ionia dışındaki bölgelerden gelen objelerin genel toplama göre oldukça önemsiz bir miktara sahip olduğu söylenebilir).

S.P. Morris'e göre Ephesos Anadolu geçmişi ve Lydia ile ilişkileri ekseninde kimliğini şekillendirmiş bir şehirdir ve Artemis kutsal alanından ele geçen sunu objeleri yanı sıra, Artemis kült heykelinin ikonografisi bu imajı güçlendirmektedir (Morris, 2006, 70). Bir yandan Lydia formlarının yerel taklitleri üretilirken, diğer yandan da İ.Ö. VII. yüzyılda Lydia hakimiyetinde olan Phrygia kökenli eserler ve onların kopyaları da kutsal alanda sunulmaktadır. Her halükarda Ephesos'da yerel habitus'un büyük ölçüde Lydia etkisi altında şekillendiği anlaşılmaktadır (Herodotos'a göre Ephesos Lydia'lıların doğal limanıdır).

Samos Heraion kutsal alanı, Samos kentinin 8 km güneyinde, verimli bir ovanın kenarında yer alır. Hemen yanında Imbrassos nehri yer almaktadır ve hemen yakınında yer alan plaj gemilerin yanaşması için son derece uygundur. Zaten kutsal alanda, Mykale Burnu ile Samos Adası arasında yer alan boğazın hemen girişinde yer almaktadır. Kutsal alanın erken evreleri basit bir plan gösterir. Merkezi bir sunak ve hemen arkasında bir heykel kaidesi alanın kalbini oluşturmaktadır ve İ.Ö. X. ile İ.Ö VIII. yüzyıllar arasında bu sunak beş defa yeniden inşa edilmiştir (Buschlor, \& Schleif, 1933, 146-150). Bu dönem sunu objelerinin büyük çoğunluğunu elde veya çarkta biçimlendirilmiş pişmiş toprak figürinler oluşturur. Ayrıca Thessalia ve Makedonia'dan ithal edilmiş az sayıda bronz elbise aksesuarı da bulunmaktadır (Brize, 1997, 126).

Samos Heraion'da, İ.Ö. VII. yüzy1l boyunca önemli değişiklikler olduğu gözlenmektedir. Sunak 5 olarak adlandırılan ilk anıtsal sunak İ.Ö. VII. yüzyılın ikinci yarısında inşa edilmiştir (Rupp, 1983, 104). Bu sunağa çağdaş olarak etrafına naiskos benzeri küçük binalar da yapılmıştır (Brize, 1997, 125). Buna ek olarak buradaki en eski tapınak olan Hekatompedon muhtemelen İ.Ö. VII. yüzyılın ilk yarısında inşa edilmiş ve bu ilk inşaatı 650'ler civarına tarihlenebilecek ikinci evre takip etmiştir (Mallwitz, 1981, 623-631). Ayrıca anıtsal bir stoa ve bir yapay havuzun kutsal alanın güneyine konumlandırıldığı da görülür. Bütün bu düzenlemeler, kutsal alanın girişinin İ.Ö. VII. yüzyıl boyunca deniz tarafında olduğunu göstermektedir (Kyrieleis, 1993, 136).

Kıbrıs kökenli pişmiş toprak figürinler Heraion'da ele geçmiş bu tip heykelciklerin üçte birini oluştururlar ve bunların en erken örnekleri İ.Ö. 670'in hemen öncesine tarihlenmektedir. (Schmidt, 1968). Bu heykelciklerin bir süre sonra yerel taklitleri de üretilmeye başlanmıştır ve 
kalıpta üretilen yerel taklitler, Heraion'da ele geçen erken yerel üretim figürinlerden kalite olarak çok daha üstündür (Brize, 1997, 127). Ancak Misır kökenli bronz heykel, silah, kaplar ve koşum takımları gibi değerli bronz objeler belki de önemli grubu oluştururlar ve kutsal alanın ziyaretçilerinin olağanüstü zenginliğini ortaya koyarlar (Jantzen, 1972). Heraion, Olympia Zeus ve Delphoi Apollon kutsal alanları ile birlikte, Hellen Dünyası'nda en çok üçayaklı kazanın ortaya çıkarıldı ̆̆ üç merkezden birisidir (Saint-Pierre, 2005, 303). Ayrıca Asur, Babil, Urartu ve Luristan kökenli değerli bronz objeler de bulunmaktadır (Saint-Pierre, 2005, 360). Kuzey Suriye ve Geç Hitit Kentleri ve Fenike kökenli pek çok obje de gözlemlenebilir. Bütün bu sunu objesi çeşitliliği içinde, kadın dünyası ile ilişkilendirilebilecek takı ve elbise süslerinin hiç var olmaması ise özellikle dikkat çekicidir (Polignac, 1997, 116).

Samos Heraion'da Akdeniz Dünyası'nın dört bir yanından sunu objeleri bulunmaktadır. Saint Pierre, mevcut yayınları tarayarak, bu objelerin nitelik ve nicelikleri üzerine detaylı istatistikler ortaya koymuştur (Saint Pierre, 2005, 357-360). Ortaya koyduğu verileri kısaca özetlenirse, toplamda 1137 adet oryantal objenin kazılarla ortaya çıkarıldığ1 görülebilir. Bunların içerisinde pişmiş toprak eserler (toplam 485 obje) ve bronzlar (toplam 333 obje) en büyük iki grubu oluşturmaktadır. Ayrıca 140 adet fayans obje dikkat çekmektedir. Bu objelerin kökenlerine bakıldığında ise, Kıbrıs'ın (toplam 643 sunu objesi) ve Mısır'ın (toplam 153 adet sunu objesi) en önemli kaynakları oluşturdukları gözlenmektedir. Buna karşılık Lydia sadece 1, Phrygia ise 34 adet objeyle temsil edilmektedir. İlginç bir grubu ise, Geç Hitit ve Urartu kökenli eserler oluşturur ve Kuzey Suriye eserleri ile beraber toplamda 89 objelik bir grubu meydana getirirler. Yerel üretim sunu objelerinin ise bu genel toplamda daha küçük bir yüzdeyi oluşturdukları görülebilir. En büyük grubu 250 kadarı kazılarda ortaya çıkarılmış pişmiş toprak figürinler oluşturur (Alroth, 1989, 22). Ayrıca 32 adet kalkerden ev modeli ele geçmiştir (Schattner, 1990, 40-84). Bir diğer ilginç grubu ise, toplamda 20 kadar ele geçmiş olan ahşap gemi modelleri oluşturur (Kyrieleis, 1980). Ayrıca kutsal alanda tespit edilmiş iki adet yaklaşık 25-30 metre uzunluğunda kaide, İ.Ö. VII. yüzyılda gerçek gemilerin de kutsal alana sunulduğunu göstermektedir (Walter, 1990, 83 ve 89).

Daha önce belirtildiği gibi kutsal alanın mekansal organizasyonu denize dönüktür ve buradaki pek çok sunu objesi denizcilik ve uzak ülkelerle ilişkili gibi gözükmektedir. Özellikle anıtsal sunak ve deniz kıyısı arasındaki bölgede zengin buluntular keşfedilmiştir ve sunu objelerinin yanı sıra, İ.Ö. VII. yüzyılın ikinci yarısına tarihlenen binlerce çanak çömlek parçası, hayvan kemikleri ve demir şişlerle karışmış olarak bu bölgeden gelmektedir (Brize, 1997, 128). Bütün bu veriler, Samos Heraion'un Ege Denizi deniz yolları üzerinde özel bir öneme sahip olduğunu gösterir niteliktedir ve kutsal alan ziyaretçileri uzak/deniz aşırı ülkelere ulaşma kabiliyetlerini sergilemek için özel bir çaba sarfetmişlerdir (Polignac, 1997, 119).

Görüldüğü gibi Samos Heraion ve Ephesos Artemis kutsal alanları zenginlik ve sunu objelerinde çeşitlilik açısından diğer bütün Ionia kutsal alanlarının önünde yer almaktadırlar. Yine de ilk bakışta sunu kontekstlerinin belirgin bir şekilde farklılaştığı gözlenebilmektedir. Bir tarafta Samos Heraion kutsal alanında Akdeniz'in dört bir yanından sunu objeleri, bu alanın deniz yolları üzerindeki özel konumunun altını çizer şekilde buraya sunulur. Özellikle Mısır kökenli değerli bronzlar, sunuda bulunanların zenginliği ve sosyal statüsünü bütün görkemiyle ortaya koymaktadır. Yine de, bütün sunu objesi zenginliği ve Hellen üretimi olmayan obje bolluğuna karşl1ık bütün ritüellerin alanda yer alan tek sunak etrafında şekillendiğinin altını çizmek gereklidir.

Öte yanda Ephesos Artemis kutsal alanı yüzünü daha ziyade Küçük Asya'nın iç kısımlarına ve burada bulunan krallıklara dönmüş gibi görünmektedir. Burada özellikle altın ve elektron gibi değerli madenlerden takıların sunu objesi olarak tercih edildiği görülmektedir. Bu objelerin özellikle Lydia ile yakın ilişkili olduğu gözlemlenebilmektedir. Samos'dan farklı şekilde, burada 
farklı ritüeller bir arada sergilenebilmektedir ama anıtsal bir tapınağın varlığı, bütün ikincil kült aktiviteleri üzerinde Artemis kültünün hakimiyeti olduğunu ortaya koymaktadır.

Her halükarda bütün kanıtlar, İ.Ö. VII. yüzyıl da hellenlerin çevrelerindeki dünya ile ilgili algılarının genişlediğini göstermektedir ve bu durum dinsel hayatlarını da etkilemiştir. Akdeniz iletişim ağları içerisinde yer almak ve deniz yolları vasıtası ile Akdeniz Dünyası ile bağlantının artması, İ.Ö. VII. yüzyıl boyunca Ionia kutsal alanlarını etkisi altına almıştır. Özellikle oryantal sunularının artması, bu farklı perspektiflerin oluşumu bağlamında açıklanabilir. Altı çizilmesi gereken bir diğer nokta, sunu ve kurbanla ilgili var olan ritüellerin ve sunu objesi formlarının kökünden değişmediği, ama ritüelde kullanılan objelerin içerisine doğu formlu/orijinli örneklerin katıldığıdır ve bu özünde dinsel değil sosyolojik değişimlerle ilişkili olarak algılanabilir. Ancak Ephesos örneği, hinterlandının doğal limanı görünümündeki bir kentte sosyal sermayenin alternatif iletişim ağlarıyla ilişkili olarak da şekillenebileceğini göstermektedir.

\section{KAYNAKÇA}

Alroth, B. (1989). Greek Gods and Figurines. Uppsala.

Bammer, A. (1990). "A Peripteros of the Geometric Period in the Artemision of Ephesus". AnatSt 40, 137-160.

Bammer, A. (1991a). "Les sanctuaires de l'Artémision d'Ephèse". Ed. R. Etienne, \& M. T. Le Dinahet, L'espace sacrificiel dans les civilizations méditerranéennes de l'Antiquité, 127-130. Paris.

Bammer, A. (1991b). "Les Sanctuaires de VIII et VIIe siècles à l'Artémision d'Éphèse”. RA, 1991, 63-84.

Bammer, A. (1991/92). "Multikulturelle Aspekte der frühen Kunst im Artemision von Ephesos". Öjh, 61, Beiblatt, 17-54.

Bammer, A. (1992). "Ivories from the Artemision at Ephesus". Ed. J. L. Fitton, Ivory in Greece and the Eastern Mediterranean from the Bronze Age to the Hellenistic Period, 185-204. London.

Bammer, A. (1993). "Fouilles à l'Artémision d'Éphèse (Période Géometrique et Archaique) Nouvelles Données". Révue Archéologique, 1993, 187-199.

Bammer, A. (1998). "Sanctuaries in the Artemision of Ephesus". Ed. R. Hagg. Ancient Greek Cult Practise from the Archaeological Evidence, 27-47. Stockholm.

Bammer, A. (2008). "Der Peripteros und sein Vorganger". Ed. U. Muss. Die Archaologie der ephesischen Artemis, 243-249. Wien.

Bayburtluoğlu, C. (1975). Erythrai, Coğrafya, Tarih, Kaynaklar. Kalıntılar. Ankara

Bayburtluoğlu, C. (1977). Erythrai II, Pişmiş Toprak Eserler. Ankara.

Beaumont, L.A., \& Archontidou-Argyri, A. (1999). "New Work at Kato Phana, Chios: The Cato Phana Archaeological Project". BSA, 94, 265-287.

Boardman, J. ( 1967). Excavations in Chios, 1952-1955: Greek Emporio. BSA Suppl.6, London

Braudel, F. (1989). Akdeniz ve Akdeniz Dünyası. İstanbul.

Brize, P. (1997). “Offrandes de l'Epoque Géométrique et Archaique à l'Héraion de Samos”. Ed. J. De la Genière. Héra: Images, Espaces, Cultes. 123-139. Naples.

Burkert, W. (1992). The Orientalizing Revolution. Near Eastern Influence on Greek Culture in the Early Archaic Age. London

Buschlor E., \& Schleif, H. (1933). "Heraion von Samos: Der Altarplatz der Frühzeit". MDAI (A) 58, 146-173.

Cook, J. M. (1951). "Archaeology in Greece- Old Smryna”. JHS 71, 231-253.

Dewailly, M. (2001). "Le Sanctuaire d'apollon a Claros. Place et fonction des dieux d'apres leurs images". MEFRA 113, tome 1, 365-382.

Etienne, R. (2006). "Compte rendu". Ed. W. V. Harris. Rethinking the Mediterranean. Oxford University Press, Oxford (2005). Topoi, 14, 743-746.

Etienne, R. (2010). "Historiographie, théories et concepts". Ed. R. Etienne. La Méditerranée au VIIe siècle av. J.-C., 3-26. Paris.

Forstenpointner, G., Kerschner, M., \& Muss, U. (2008). "Das Artemision in der spaten Bronzezeit und 
der frühen Eisenzeit”. Ed. U. Muss, Die Archaologie der ephesischen Artemis, 33-46. Wien

Foxhall, L. (1998). "Cargoes of the heart's desire. The character of trade in the archaic Mediterranean world”. Ed. N. Fisher, \& H. Wan Wees, Archaic Greece. New Approaches and New Evidence, $295-$ 309. Swansea.

Gans, U. (1991). "Die Grabung auf dem Zeytintepe". IstMitt, 41,137-140.

Greaves, A. M. (2000), "Miletos and the sea: a stormy relationship". Ed. G. J. Oliver. The Sea in Antiquity, 39-62. Oxford.

Gschwantler, K., \& Freiberger, V. (2008). Goldschmiedetechnische Beobachtungen zu den Löwenkopffibeln aus dem Artemision in Ephesos. Ed. U. Muss. Die Archaologie der ephesischen Artemis, 185-200. Wien.

Guralnick, E. (1992). "East to West : Near Eastern Artifacts from Greek Sites. Ed. Editions Recherches sur les Civilisations". La circulation des biens, des personnes et des idées dans le Proche-Orient ancient. Rencontre Assyriologique Internationale 8-10 juillet 1991, 327-338. Paris.

Gültekin, H. (1968). "Erythrae kazısında bulunan fayans figürinler”. Türk AD, 17, 101-116.

Harris, W.V. (2005). "The Mediterranean and Ancient History". Ed. W.V. Harris. Rethinking the Mediterranean, 1-42. Oxford.

Heredotos, The Persian Wars. Ed. A. D. Godley $\left(2004^{12}\right)$. Cambridge: Loeb.

Horden, P., \& Purcell, N. (2000). The Corrupting Sea. Oxford.

Hölbl, G. (2008a). “Agyptisches Kulturgut im archaischen Artemision”. Ed. U. Muss. Die Archaologie der ephesischen Artemis, 209-222. Wien

Hölbl, G. (2008b). “Akdeniz'de İ.Ö. I. binyıl başlarında Mısır Kültür Varlığı”. Ed. W. Seipel. Efes Artemisionu. Bir Tanrıçanın Kutsal Mekanı, 281-295. İstanbul

Jantzen, U. (1972). Agyptische und Orientalische Bronzen aus dem Heraion von Samos. Samos VIII, Bonn.

Kilian-Dirlmeier, I., (1985). "Fremde Weihugen im griechischen Heiligtümer von 8. Bis zum Begin des 7. Jahrhunderts". JRGZM 32, 215-254.

Klebinder-Gauss, G. (2008a). Weihagen aus Bronze. Ed. U. Muss. Die Archaologie der ephesischen Artemis, 149-156. Wien.

Klebinder-Gauss, G. (2008b). "Ephesos und seine Beziehungen zur phrygischen Bronzekunst". Ed. U, Muss. Die Archaologie der ephesischen Artemis, 235-240. Wien.

Kraft, J. C., Kayan, İ., Brückner, H. \& Rapp, G. (2000). “A Geologic Analysis of Ancient Landscapes and the Harbors of Ephesus and the Artemision in Anatolia". Öjh, 69, 175-232.

Kraft J. C., Kayan İ., \& Brückner H. (2001). "The Geological and Paleogeographical Environs of the Artemision”. Ed. U. Muss. Der Kosmos der Artemis von Ephesos, 123-133. Wien.

Kyrieleis, H. (1993). "The Heraion at Samos". Ed. N. Marinatos, \& R. Hagg. Greek Sanctuaries New Approaches, 125-153. London, New York.

Kyrieleis, H. (1980). “Archaische Holzfunde aus Samos”. MDAI (A), 95, 87-147.

Linders, T. (1987). “Gods, Gifts, Society”. Ed. T. Linders, \& G. Nordquist. Gifts to the Gods, 115-122. Uppsala.

Mallwitz, A. (1981). "Kritisches zur Architektur Griechenlands im 8. und 7. Jahrhundert”. AA, 1981, 599-642.

Morris, S. P. (2006). “The View from East Greece. Miletus, Samos and Ephesus”. Ed. C. Riva, \& N.C. Vella. Debating Orientalization. Multidisciplinary approaches to change in the ancient Mediterranean, 66-84. London.

Muss, U. (2008a). “Gold des Meeres: Bernstein aus dem Artemision von Ephesos”. Ed. U. Muss. U., Die Archaologie der ephesischen Artemis, 95-102. Wien .

Muss, U. (2008b). "Elfenbein und Bein aus dem Artemision von Ephesos”. Ed. U. Muss. Die Archaologie der ephesischen Artemis, 103-116. Wien.

Patera, I. (2006). Offrir en Grèce ancienne: rites et objets autour de certains sanctuaires et fêtes de Déméter. Yayınlanmamış DoktoraTezi. EPHE. Paris.

Polignac, F. De. (1997). "Héra, le navire et la demeure: offrandes, divinité et société en Grece archaique". Ed. J. De la Genière. Héra: images, espaces, cultes, 113-122. Naples. 
Rupp, D. W. (1983). "Reflections on the Development of Altars in the Eight Century B.C". Ed. R. Hagg. The Greek Renaissance of the Eight Centuries B.C.: tradition and innovation, 101-107. Stockholm.

Saint-Pierre, C. (2005) Les offrandes orientales dans les sanctuaires du monde grec à l'époque archaique. Yayınlanmamış Doktora Tezi. Université Paris 1. Paris

Schattner, T.G. (1990), Griechische Hausmodelle: Untersuchungen zur frühgriechischen Architektur. MDAI (A), Beiheft 15. Berlin.

Schmidt, G. (1968). Kyprische Bildwerke aus dem Heraion von Samos. Samos VII, Bonn.

Senff, R. (2006). "Form and Function of Sanctuaries in Archaic Miletos". REA, 108, 159-172.

Simon, C. G. (1997). "The Archaeology of Cult in Geometric Greece. Ionian Temples, Altars and Dedications". Ed. S. Langdon. New Light on a Dark Age, 125-143. Columbia.

Simon, C. G. (1986). The Archaic Votive Offerings and Cults of Ionia. Yayınlanmamış Doktora Tezi. Ann Arbor.

Treziny, H. (2006). Urbanisme Archaique des villes Ioniennes: Un Point de vue Occidental. REA, 108, 225-247.

Walter, H. (1990). Das Griechische Heiligtum dargestellt am Heraion von Samos. Stutgart. 
